\title{
Effectiveness of an osteopathic treatment on the autonomic nervous system: a systematic review of the literature
}

\author{
Verena Rechberger ${ }^{1}$, Michael Biberschick ${ }^{2}$ and Jan Porthun ${ }^{3^{*}}$ (D)
}

\begin{abstract}
Objective: The objective of this systematic review was to evaluate the effectiveness of an osteopathic treatment on the autonomic nervous system (ANS). For this purpose, published primary studies were analysed and critically evaluated.
\end{abstract}

Method: To generate this review, 15 electronic databases were systematically searched for studies. Randomized clinical controlled trials (RCT) and clinical controlled trials (CCT) are included in the review and evaluated with appropriate assessment tools (Downs and Black Checklist and the checklist from Kienle and Kiene).

Results: 23 published studies (10 RCT, 1 clinic multi-centre study, 1 CCT, 5 randomized cross-over studies, 5 randomized pilot studies and 1 single case study) are included in this review. The studies were evaluated with the assessment tools according to their quality. 3 studies are graded as high quality, 11 as moderate and 8 as low-quality studies.

Conclusion: The included published studies represent a good level of evidence. Due to a small number of subjects and no follow-ups, the methodological quality is rated as moderate. A significant change on the ANS was shown in studies including High-Velocity Low-Amplitude Techniques (HVLAT). No statement could be drawn in studies in which they used cranial osteopathic techniques due to the lack of methodological quality. A significant change on the ANS is shown in the treatment of the suboccipital region. In studies which evaluated the effectiveness of mobilization in the cervical and thoracic region, no statement could be displayed due to a low level of evidence. None of the findings in these studies have given statements if ANS activation takes place in the sympathetic or parasympathetic system.

Keywords: Osteopathy, Autonomic nervous system, Treatment techniques

\section{Background}

The osteopathic health care with its philosophy and principles of practice is a holistic, person-centred treatment concept with body structure (anatomy) and body function (physiology) as a unit [1].

The osteopathic treatment principles are integrated in the five osteopathic treatment models which are categorized as followed: postural-biomechanical model, respiratory-circulatory model, bioenergetic-metabolic

\footnotetext{
*Correspondence: jan.porthun@ntnu.no

${ }^{3}$ Department of Health Sciences Gjøvik, Norwegian University of Science and Technology, Gjøvik, Norway

Full list of author information is available at the end of the article
}

model, biopsychosocial model and neurologic-anatomic model [2].

The treatment of the autonomic nervous system (ANS) is an important sequence of the treatment procedures as it is involved in the regulation of the homoeostasis of the body functions, e.g. cardiovascular system, blood pressure, temperature [3]. Therefore, a good function of the innervations from the 1st centre of the ANS to the target organ is required [3]. Imbalances between the sympathetic and parasympathetic over a longer period of time can lead to various symptoms in the body. It has an influence on, e.g. the vasoconstriction of the blood vessels in the gastro-intestinal region, vasodilatation in the skeletal muscles, low or high heart 
rate, changes in the secretion of glands, changes in the bronchial muscles and glands which can be revealed by the body as a malfunction of an organ [4].

A wide variety of manual treatment techniques is used by osteopaths to improve the physiological functions in the body and to regain homoeostasis which has been altered by somatic dysfunction [5]. Osteopathic manipulation techniques are defined as followed: thrust manipulation techniques (High-Velocity Low-Amplitude Thrust), soft tissue techniques (myofascial release techniques), Counterstrain techniques, Balanced Ligamentous Tension and Ligamentous Articular Strain techniques, visceral techniques, osteopathic craniosacral techniques [1].

Welch and Boone [6] reported in their study in 2008 that cervical and thoracic manipulation techniques influence the activity of the ANS. A rib raise technique, which Henderson et al. [7] discovered in their study, also has an influence on the ANS activity. Other osteopathic treatment techniques such as craniosacral compression techniques on the fourth ventricle of the brain also show a change in the ANS activity which Curi et al. [8] studied in 2017.

Unfortunately, the number of studies done in this field displays indifferent results in the change of the ANS activity.

The aim of the current review is to evaluate with the existing literature, if an osteopathic treatment affects the autonomic nervous system and if a certain treatment in different body regions has an effect on the sympathetic or parasympathetic nervous system and can lead to changes in different malfunctions in the body system as mentioned above. Study search was restricted by language barriers (only English, German) due to the writer's language limitations.

\section{Main text}

\section{Methods and materials}

A comprehensive search of the existing literature was undertaken to identify published original research examining the effectiveness of treatments to the ANS. In accordance with the PRISMA statement, the review techniques in this study followed their standards [9]. The included studies for this review were carried out from researchers all over the world, e.g. Australia, Brazil, Canada, France, Italy, Japan, Malaysia, New Zealand, Spain, UK, USA.

\section{Inclusion criteria}

There were no time limits set for the research of the literature.
Types of studies The present systematic review included randomized clinical controlled trials (RCT), clinical controlled trials (CCT), single case studies, multi-centre studies, pilot studies and observational studies.

Types of interventions All studies in the field of osteopathic manipulative treatments (OMT), physiotherapy, chiropractic, manual medicine were included in the search strategy. Some treatment techniques in these professional groups overlap, which is why they were all included in the search.

\section{Exclusion criteria}

Articles were excluded if they were not written in English or German, did not present original empirical data or only an abstract was available or if they only represented active physiotherapy in the study. Also excluded were articles in which OMT was combined with other therapy forms. Conference proceedings, editorials, letters or seminar dossiers were excluded too.

\section{Outcomes}

The primary outcome was to estimate the efficacy or effectiveness of an osteopathic treatment on the ANS. As a second outcome, the effect of treatment techniques in different body regions for sympathetic and parasympathetic nervous system was evaluated. Any kind of an adverse event was a second outcome.

\section{Data sources and searches}

A systematic literature search was performed from March 12, 2018 to April 14, 2018 in the following electronic databases: PubMed, Chiroindex, The Cochrane Library, BioMedCentral, Osteomed Dr., EBSCO-psycharticles, PEDRO, Springerlink, Embase-Elselvier, LIVIVO, ScienceDirect, AMED, EBSCO-CHINHAL, pubpsych. zipd.de, Chiropractic \& Manual Therapies.

The following search terms, defined by MeSH (Medical subject headings), were used: osteopathic medicine $(\mathrm{OM})$, autonomic nervous system (ANS), parasympathetic nervous system (PNS), sympathetic nervous system (SNS), musculoskeletal manipulations, chiropractic, therapy/therapeutic use, manual therapy, mobilization. The search was supplemented by a manual search in the reference list for all relevant studies that were not listed when searching the electronic databases and by citation tracking of the identified trials. 
Study selection The author of this review systematically screened the titles and abstracts of the results from the search strategy (1st selection). Potential studies were read in full text and once more evaluated for the inclusion in the current review (2nd selection).

Data extraction Data were extracted by the author of the current review. For the purpose of this review, the information extracted from the included papers were author, source, and design, characteristics of the participants/aim of the study, sample, intervention, and summary of findings.

Dealing with missing data If the article did not contain sufficient information or was not completed, the authors were contacted for additional information or the full article.

Quality assessment The summary of results was reported following the PRISMA statement [9].

The quality of evidence for each outcome in the included studies was assessed using the Downs and Black scale [10] for RCT, non-RCT studies, and for the single case studies, the checklist from Kienle and Kiene was used [11].

The Downs and Black scale is based on a checklist of 27 items and has been found to be valid for critically evaluating RCT and non-RCT studies [10]. The checklist included four categories for evaluation: reporting, external validity, internal validity/bias, internal validity/confounding. The Downs and Black scale specifies 4 levels of quality using this scoring system which is categorized as followed in Table 1: strong, moderate, limited or poor quality [12].

The checklist from Kienle and Kiene was developed to evaluate the methodological quality of single case studies, case series [11]. It consists of 11 items which are scored with zero or one point. The quality index of the scoring system is categorized with good, moderate or poor as shown in Table 2.

Table 1 Categorization of total scores of the Downs and Black Checklist [12]

\begin{tabular}{lcl}
\hline Quality index & Percentage & $\begin{array}{l}\text { Methodological } \\
\text { quality score } \\
(\mathbf{n = 2 7 )}\end{array}$ \\
\hline Strong & $\geq 75 \%$ & $\geq 21$ \\
Moderate & $50-74 \%$ & $14-20$ \\
Limited & $25-49 \%$ & $7-13$ \\
Poor & $<25 \%$ & $<7$ \\
\hline
\end{tabular}

Table 2 Categorization of total scores obtained by Kienle and Kiene [11]

\begin{tabular}{ll}
\hline Total score & Quality index \\
\hline $11-9$ points & Good \\
$9-5$ points & Moderate \\
$5-1$ points & Poor \\
\hline
\end{tabular}

\section{Results}

\section{Included studies}

Electronic search identified 2166 papers (see Fig. 1). In the first selection process after screening title and abstracts, 114 studies were left (1st selection, including duplicates). In the next step, 73 duplicates were removed. After reading the full text of 41 papers and applying the predefined inclusion criteria, 23 articles were left for the qualitative analysing (2nd selection).

\section{Excluded studies}

In the first selection process, 73 duplicates were excluded and from the 41 papers read in full text, 18 were excluded for various reasons.

Study details Of the included articles, one study [13] performed an OMT intervention based on each patient's needs and 6 studies $[8,14-18]$ dealing with cranial osteopathic manipulative medicine (OMM). 15 of the 23 studies were dealing with a healthy population. In the other articles, the included subjects were dealing with craniofascial pain and temporomandibular dysfunction (TMD) [19], hypertensive and normotensive blood pressure [8], lumbar pain vs. pain free [20], acute cervical pain vs. pain free [21], lumbar pain, cervical pain or headache [22], acute back pain [23], cervical pain and stiffness [24] and certain symptomatic region [25].

Globally, a wide range of techniques was used. The following treatment techniques were investigated: mobilization of the cervical spine [19-21], posterior/anterior mobilization of the thoracic spine [28], mobilization of the lumbar spine [23], soft tissue techniques in the cervical spine region [24, 25], HVLAT techniques in the thoracic spine $[6,15,26]$, HVLAT techniques in the lumbar spine [23, 26-28], HVLAT techniques in the cervical spine $[6,26,28-32]$ and a rib raise technique [7].

The results of the quality of the included studies scaled with the Downs and Black checklist are listed in Table 3. The single case study [25], evaluated with the checklist from Kienle and Kiene [11], scored 7 points and the result on the quality index was moderate.

The studied population ranged in size from 1 in the single case study [25] and 10 in a pilot study [16] to 539 in a clinical multi-centre study [22]. Treatment 


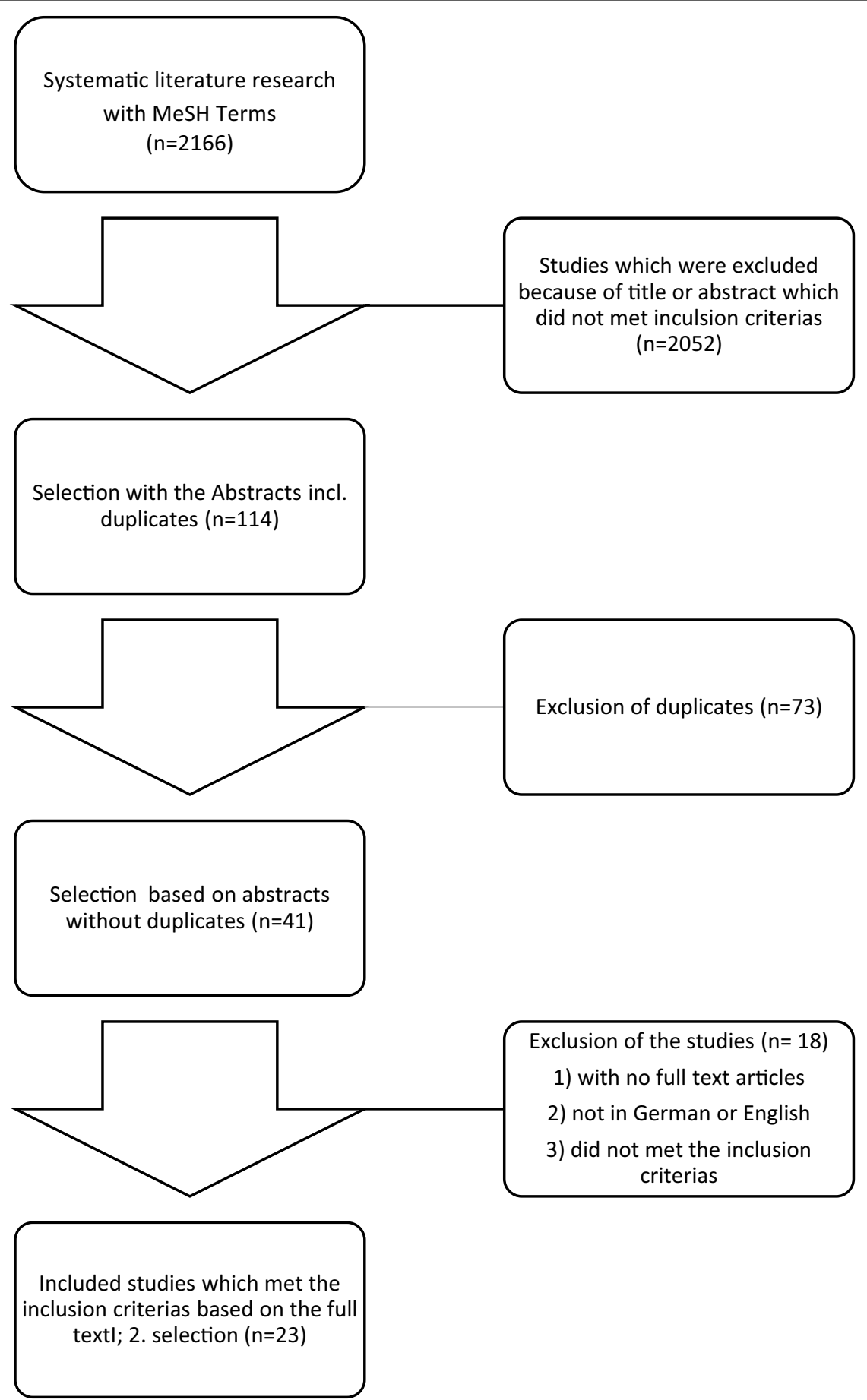

Fig. 1 Flow chart of the study selection

duration ranged from 3 times $1 \mathrm{~min}$ [26] to $45 \mathrm{~min}$ [23]. The length of treatment period differed, ranging from single treatments to regularly treatments in a period of 5 weeks. The time when measurements were taken to evaluate changes in the ANS after the treatment differs in all studies. They were taken immediately after the treatment or have follow-up measurements a few times after in different intervals (280 min after intervention). 
Table 3 Rating of the studies with the Downs and Black Scale [10]

\begin{tabular}{|c|c|c|c|}
\hline Authors & Study types & Score & Quality index \\
\hline $\begin{array}{l}\text { Budgell and Hirano } \\
\text { [31] }\end{array}$ & $\begin{array}{l}\text { Rand. cross-over } \\
\text { design }\end{array}$ & 16 & Moderate \\
\hline $\begin{array}{c}\text { Cardoso-de-Mello-e- } \\
\text { Mello-Ribeiro [18] }\end{array}$ & $\mathrm{RCT}$ & 18 & Moderate \\
\hline Chiu and Wright [27] & RCT & 11 & Limited \\
\hline Curi et al. [8] & $\mathrm{RCT}$ & 16 & Moderate \\
\hline Fornari [14] & Rand. pilot study & 18 & Moderate \\
\hline Fukada et al. [24] & $\begin{array}{l}\text { Rand. cross-over } \\
\text { design }\end{array}$ & 13 & Limited \\
\hline Gibbons et al. [32] & Rand. pilot study & 13 & Limited \\
\hline Giles et al. [29] & $\begin{array}{l}\text { Rand. cross-over } \\
\text { design }\end{array}$ & 13 & Limited \\
\hline Henderson et al. [7] & Rand. pilot study & 17 & Moderate \\
\hline Jowsey and Perry [28] & $\mathrm{RCT}$ & 18 & Moderate \\
\hline La Touche et al. [19] & $\mathrm{RCT}$ & 24 & Strong \\
\hline Milnes and Moran [16] & Pilot study & 12 & Limited \\
\hline Petersen et al. [26] & $\mathrm{RCT}$ & 13 & Limited \\
\hline Purdy et al. [30] & $\begin{array}{l}\text { Rand. cross-over } \\
\text { design }\end{array}$ & 14 & Moderate \\
\hline Roy et al. [20] & $\mathrm{RCT}$ & 19 & Moderate \\
\hline Ruffini et al. [13] & $\mathrm{RCT}$ & 23 & Strong \\
\hline Shi et al. [17] & $\begin{array}{l}\text { Rand. cross-over } \\
\text { design }\end{array}$ & 16 & Moderate \\
\hline Scoppa et al. [15] & Rand. pilot study & 10 & Limited \\
\hline Win et al. [21] & $\mathrm{RCT}$ & 21 & Strong \\
\hline Welch and Boone [6] & $\mathrm{CCT}$ & 10 & Limited \\
\hline Younes et al. [23] & $\mathrm{RCT}$ & 20 & Moderate \\
\hline Zhang et al. [27] & Clin. multi-centre study & 15 & Moderate \\
\hline
\end{tabular}

A wide range of measurements can be used to demonstrate changes in the ANS through heart rate variability (HRV) $[14,15,23]$ (quantitative marker for changes in the vegetative nervous system [33]), heart frequency, blood pressure [23], breathing rate [17], edge light pupil effect [32], distal skin conductance/skin temperature [20, $21,25]$, and also through changes in the immune [24] and endocrine system $[6,7]$.

The participants in the study groups were healthy adults or patients with pain in the body region that was tested in the study.

The subject groups in the included articles for this review were very heterogeneous and therefore, no statistical analysis of the study results was possible in this review.

Effects of interventions Table 4 provides a summary of the characteristics of each study, including treatment sessions and interventions.

\section{Discussion}

The general quality of the selected articles was good including a lot of RCTs. This is why the author concluded that overall there is a positive result towards the question if an osteopathic treatment can influence the ANS.

As the treatment techniques and the treated body regions in the included studies vary a lot, the included studies were summarized in groups for the discussion. Therefore, the heterogeneity of the articles does not allow for a statistical analysis.

\section{High-velocity low-amplitude techniques (HVLAT) in the cervical spine}

Six included articles [6, 21, 22, 24, 31, 32] investigated the effects of HVLAT techniques in the cervical spine on the ANS. Techniques in the upper and lower cervical spine in one article [21], which is categorized as strong in the Downs and Black checklist [10] and including 30 subjects show statistical changes in the ANS. Findings in another article [31] are that techniques in the upper cervical region on 25 healthy subjects expose significant changes in the ANS. In a randomized cross-over design study [24], which was assessed in limited methodological quality, changes were measured in the ANS through sympathetic relaxation. Inconsistent results are shown in one article [6], because their measurement tool varies (HRV, blood pressure, pulse rate). Only 7 out of 40 were measured with HRV, which qualifies as the gold standard. Their results show an increased parasympathetic activity in cervical techniques and sympathetic in thoracic techniques. In the randomized pilot study [32], changes in the ANS through techniques in the upper cervical region on 13 subjects were measured by use of the edge light pupil cycle time. This study points at a low level of evidence and was categorized as limited in their methodological quality. In a multisite clinical study [22], 539 subjects with cervical and lumbar pain and headache were measured with HRV after a HVLAT technique in the pain region. Despite a moderate categorization in the methodological quality, there are significant changes in the ANS measured.

Although the studies were limited regarding number of subjects, methodological quality and level of evidence, there is a significant change in the ANS in all publications. Almost all used HRV as a measurement instrument. No valid statement is possible if sympathetic or parasympathetic is more influenced by HVLAT techniques in the upper or lower cervical spine.

\section{HVLAT in the lumbar region}

2 studies included [20,23] investigated the effects of HVLAT techniques in the lumbar spine. In one study 


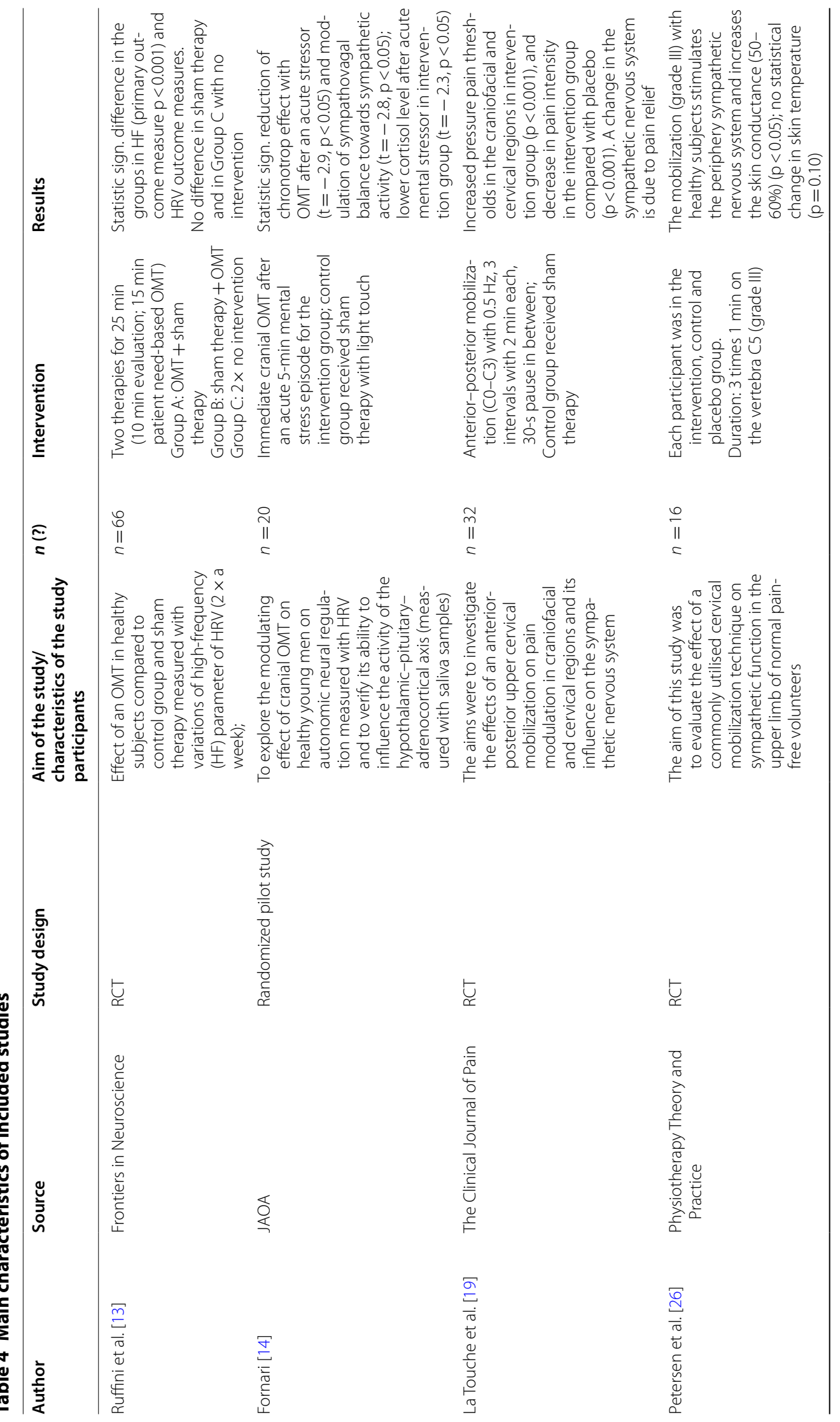




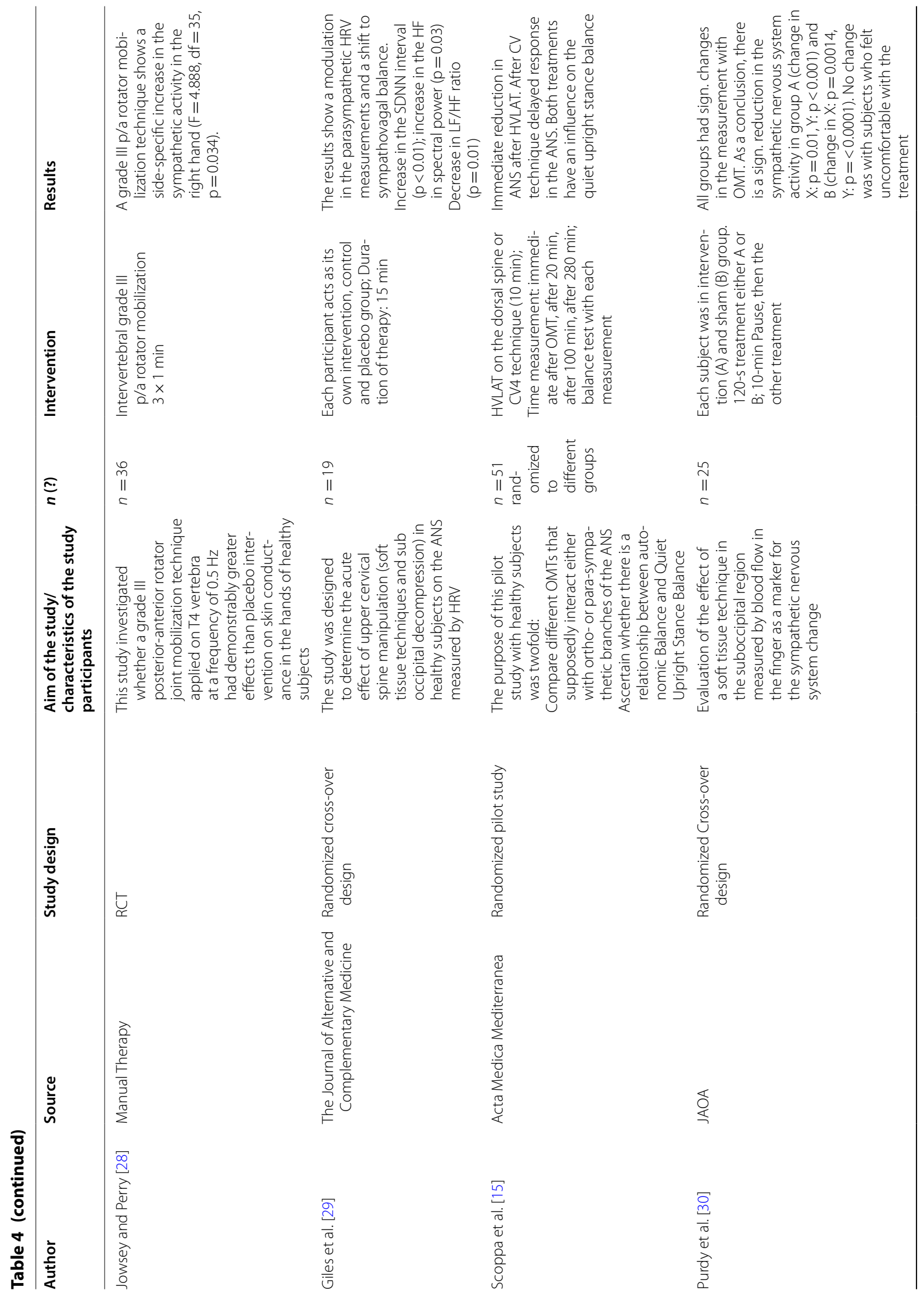




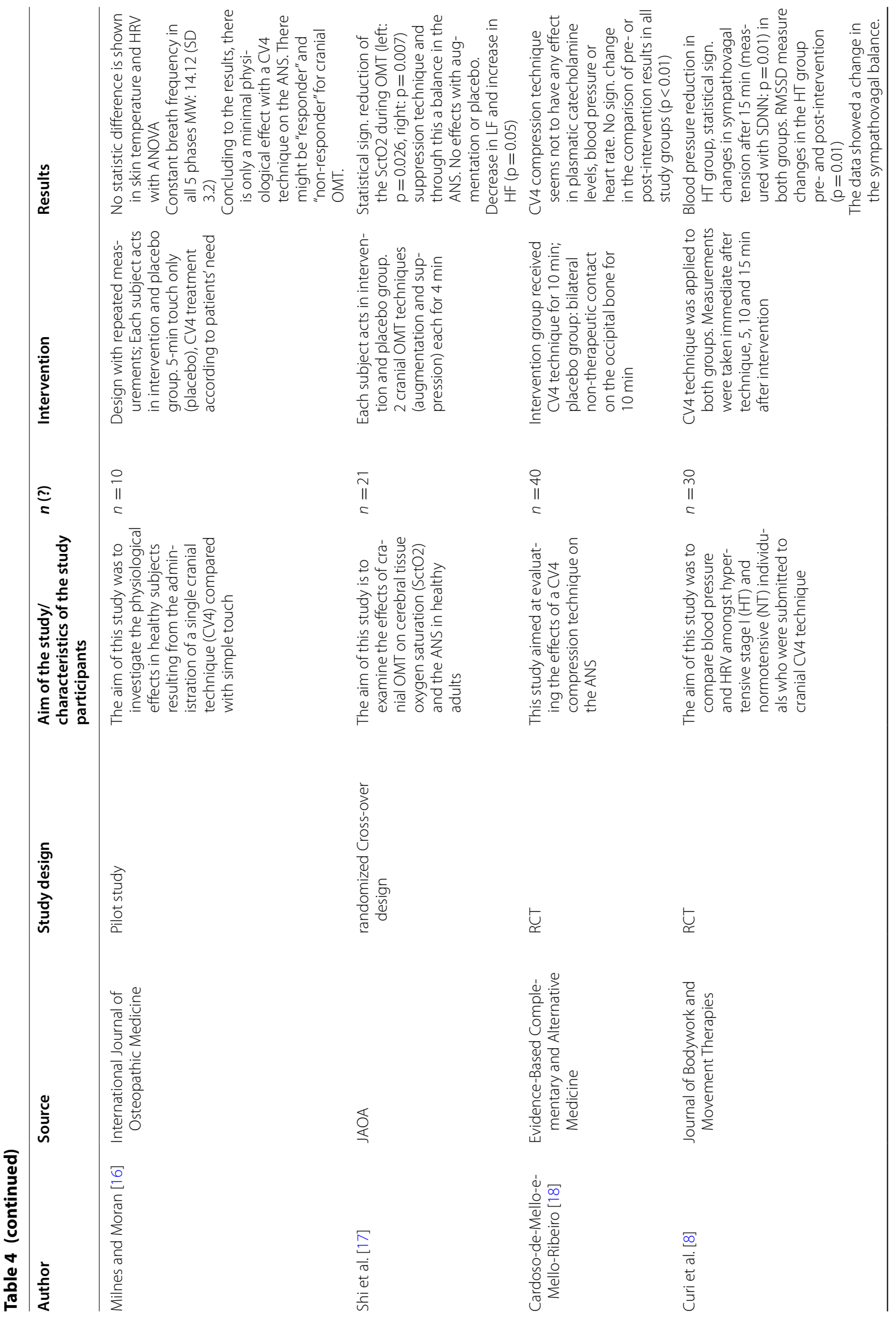




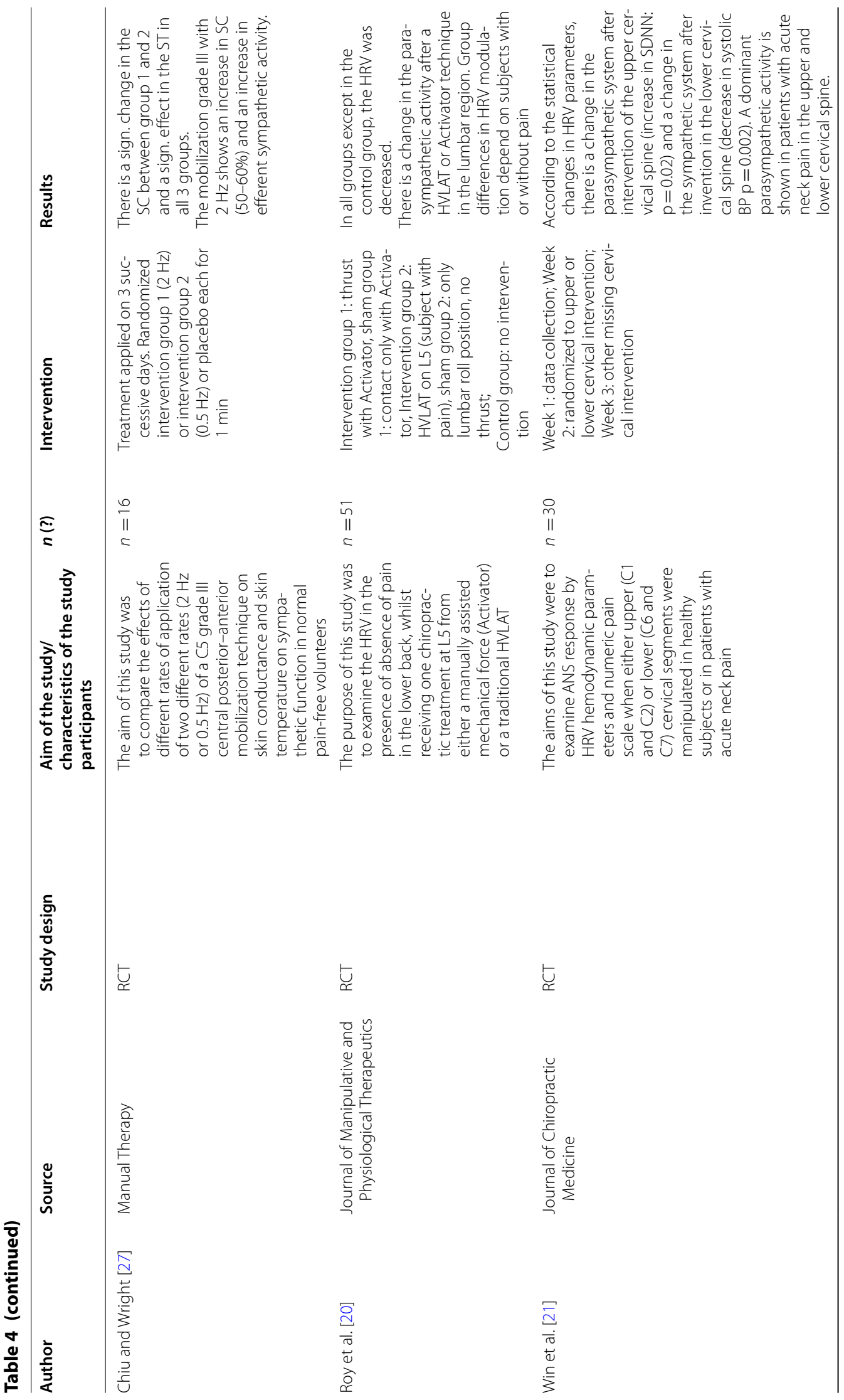




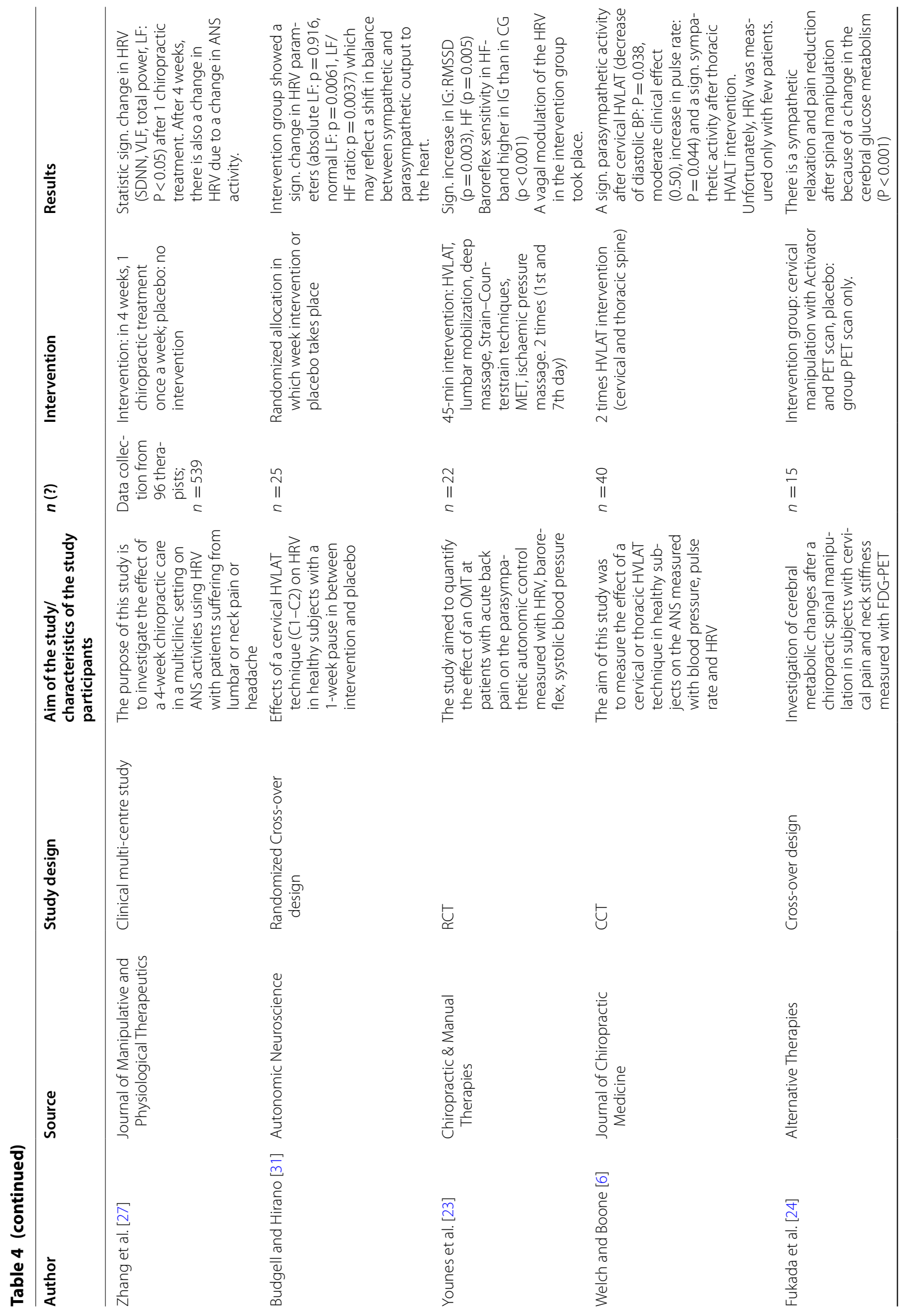




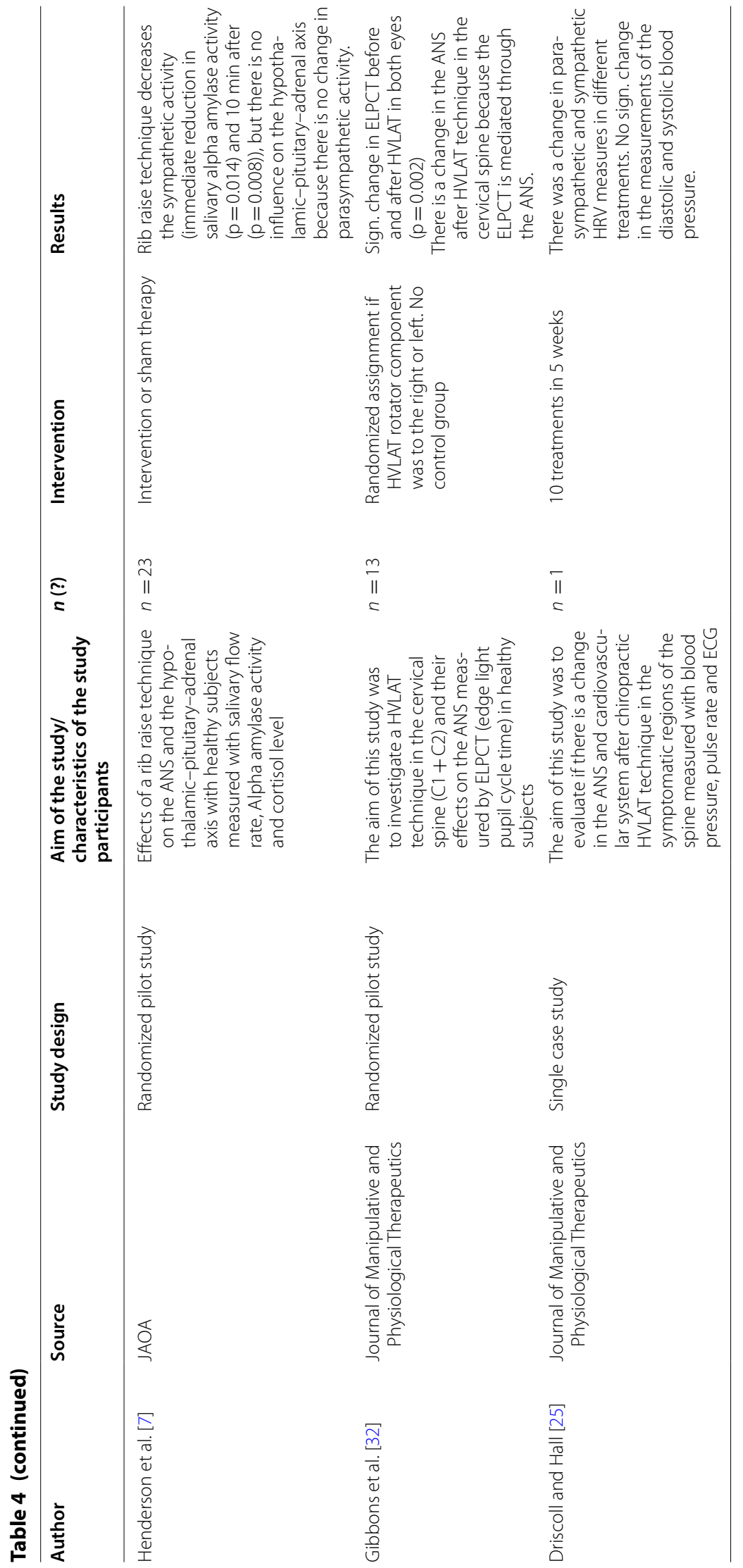


[23], the effect with 22 subjects with acute low back pain was measured through a significant change in the modulation of the ANS. In another article [20] with a good level of evidence and a moderate categorization in the methodological quality, the effect of a HVLAT technique on L5 shows a significant change in the parasympathetic activity.

In addition in a single case study [25], there were also changes in the ANS after using a HVLAT technique on the lumbar spine.

\section{Cranial OMT techniques}

In 8 studies [8, 14-18, 29, 30], the influence of a cranial OMT technique on the ANS was examined.

In an article [8], they measured changes by means of HRV and blood pressure in 30 subjects, half of them were normotensive and the other half hypertensive, with a cranial technique named CV4. The results showed a significant change in the parasympathetic activity. No follow-up was taken and no conclusion for a parasympathetic long-term effect with hypertension is possible. In one RCT [18], they compared the effect of a cranial CV4 technique and a placebo in 40 subjects. Measurement is taken with plasmatic catecholamine levels, blood pressure and heart rate. No effects related to the intervention were found. Another study [17] measured the effect of a cranial osteopathic technique by the use of HRV and cerebral tissue oxygen saturation in healthy subjects. The results show an effect in both measurement tools and therefore changes in the ANS. In an article [30] with 25 subjects, they measured the blood flow in the finger after a gentle soft tissue manipulation in the suboccipital region. Results show a slight reduction of the sympathetic activity. The level of evidence is low and the methodological quality is moderate, so the results have to be interpreted with care. In a randomized cross-over design [29], it was studied if a so-called suboccipital decompression and a soft tissue technique in this region on 19 subjects influence the parasympathethic system and the N. Vagus measured by HRV. Results show a significant change in the ANS. The methodological quality is limited and the number of participants is small which lowers the evaluation. In a pilot study [14], 20 subjects were treated with craniosacral techniques after an acute stressor. Changes were measured by HRV and cortisol level samples in saliva. The results show a reduction on the ANS and a prevention of the increase in the cortisol level. A pilot study [16] compared the effects of a craniosacral CV4 technique and a placebo therapy. The results on 10 subjects showed a very low impact on the ANS. In a pilot study [15] it was measured, if a HVLAT in the thoracic spine region or a craniosacrale $\mathrm{CV} 4$ technique shows more changes in the ANS. The results show that a CV4 technique influences sympathovagal balance and the HVLAT reduces the sympathetic system.

According to all the results in these studies, there is a tendency to a positive change in the ANS. A significant change was not reported. Only techniques in the suboccipital region showed significant changes in the ANS.

\section{Mobilization techniques in the thoracic and cervical spine}

In 4 studies [19, 26-28], the influence of mobilization techniques in thoracic or cervical spine areas on the ANS measured through changes in the upper extremity was examined. Results of this investigations show that there is an alteration in the vegetative nervous system. No valid statement is possible if it is in the 1st, 2nd, or 3rd centre of the ANS. An RCT study [19] measured the effect of an anterior/posterior mobilization of the upper cervical spine on the pain reduction in the craniofascial region and on the TMD. The pain reduction is related to changes in the sympathetic nervous system. The study has a good level of evidence. In another RCT [28], they investigated the effect of a posterior/anterior rotation mobilization in the thoracic spine. Significant changes in the sympathetic nervous system were measured in the hands. The level of evidence of this study is good and the methodological quality was rated moderate. In one article [26], they measured the effect of mobilization of the vertebra $\mathrm{C} 5$ on the sympathetic function of the upper extremity. The results show a significant increase in the skin conductance. The results are limited as the methodological quality is poor and the number of probands is only 16 . The effect of posterior/anterior mobilization in the cervical spine with $0.5 \mathrm{~Hz}$ or $2 \mathrm{~Hz}$ on the sympathetic function of the upper extremity was investigated in an RCT [27]. The result shows a change in the skin conductance which means an increase in the efferent sympathetic activity. Considering the outcomes of the study, it has to be said that the results of the measurement parameters are very inconsistent.

Two $[7,13]$ additional studies, which were not summarized in one of the groups above, are discussed in the following text paragraph.

In an RCT [13], they investigated the effect of an osteopathic treatment on 66 subjects with placebo and control group measured by HRV. Results show a statistical significant change in the ANS.

In a randomized pilot study [7], the effect of a rib raise technique on the ANS and the hypothalamicpituitary-adrenal axis using non-invasive biomarkers was investigated. The results suggest that there is a 
change on the ANS, the methodological quality is moderate and the level of evidence is good.

\section{Conclusions}

Results from this review showed that studies on the effectiveness of OMT on the ANS are scarce in subjects, heterogeneous and limited in the methodological quality. Nevertheless, a conclusion if the efficacy of OMT is given can be answered positively. No conclusive statement if the ANS can be influenced by cranial OMT can be reported. Also, no declaration can be made if a certain treatment in an area can have more influence on the sympathetic or parasympathetic nervous system.

Further, high-quality research with a larger number of subjects should be done in this field.

\section{Authors' contributions}

VR: collecting and analysing data. MB: study design and methodology. JP: study design and methodology, reviewing the manuscript. All authors read and approved the final manuscript.

\section{Funding sources}

None.

\section{Ethics approval and consent to participate}

Not necessary.

\section{Competing interests}

The authors have no personal financial or institutional interest in any of the materials or devices described in this article.

\section{Author details}

${ }^{1}$ Vienna School of Osteopathy, Donau University Krems, Vienna, Austria. ${ }^{2}$ Therapiegemeinschaft Holochergasse, Vienna, Austria. ${ }^{3}$ Department of Health Sciences Gjøvik, Norwegian University of Science and Technology, Gjøvik, Norway.

Received: 15 May 2019 Accepted: 15 October 2019

Published online: 25 October 2019

\section{References}

1. Nicholas AS, Nicholas EA. Atlas osteopathischer Techniken, 1. München: Urban und Fischer; 2009.

2. Mayer J. (Hrsg.) Standen, Lehrbuch Osteopathische Medizin, 1. München: Elselvier; 2016.

3. Dierlmeier D. Nervensystem in der Osteopathie Periphere Nerven, Gehirn- und Rückenmarkshäute. Vegetativum: Thieme; 2015.

4. Trepel M. Neuroanatomie: Struktur und Funktion; mit Tabellen, 2. überarbeitete ed. Mär. München; Jena: Urban und Fischer; 1999.

5. Benchmarks for training in traditional osteopathy. Geneva: World Health Organization; 2010.

6. Welch A, Boone R. Sympathetic and parasympathetic responses to specific diversified adjustments to chiropractic vertebral subluxations of the cervical and thoracic spine. J Chiropr Med. 2008;7(3):86-93.

7. Henderson AT, Fisher JF, Blair J, Shea C, Li TS, Bridges KG. Effects of rib raising on the autonomic nervous system: a pilot study using noninvasive biomarkers. J Am Osteopath Assoc. 2010;110(6):324.

8. Curi AC, Alves AS, Silva JG. Cardiac autonomic response after cranial technique of the fourth ventricle (cv4) compression in systemic hypertensive subjects'. J Bodyw Mov Ther. 2017;22:666-72.
9. Liberati A, et al. The PRISMA statement for reporting systematic reviews and meta-analyses of studies that evaluate health care interventions: explanation and elaboration. PLoS Med. 2009;6(7):e1000100.

10. Downs SH, Black N. 'The feasibility of creating a checklist for the assessment of the methodological quality both of randomised and non-randomised studies of health care interventions. J Epidemiol Community Health. 1998;52(6):377-84.

11. Kienle GS, Kiene H. Kriterien für die Erstellung therapeutischer Einzelfallberichte in der Onkologie. Merkurstab. 2003;56(1):2-5.

12. Jäkel A, von Hauenschild P. Therapeutic effects of cranial osteopathic manipulative medicine: a systematic review. J Am Osteopath Assoc. 2011;111(12):685.

13. Ruffini N, D'Alessandro G, Mariani N, Pollastrelli A, Cardinali L, Cerritelli F. Variations of high frequency parameter of heart rate variability following osteopathic manipulative treatment in healthy subjects compared to control group and sham therapy: randomized controlled trial. Front Neurosci. 2015;9:272

14. Fornari Mauro. Single osteopathic manipulative therapy session dampens acute autonomic and neuroendocrine responses to mental stress in healthy male participants. J Am Osteopath Assoc. 2017:117:559-67.

15. Scoppa F, Pirino A, Belloni G, Gallamini M, Messina G, lovane A. Postural and autonomic modifications following osteopathic manipulative treatment (omt): comparison between two techniques: a pilot study. Acta Medica Mediterr. 2018;2:431-6.

16. Milnes K, Moran RW. Physiological effects of a CV4 cranial osteopathic technique on autonomic nervous system function: a preliminary investigation. Int J Osteopath Med. 2007:10(1):8-17.

17. Shi X, Rehrer S, Prajapati P, Stoll ST, Gamber RG, Downey H. Effect of cranial osteopathic manipulative medicine on cerebral tissue oxygenation. J Am Osteopath Assoc. 2011;111(12):660.

18. Cardoso AP, Rodríguez-Blanco C, Riquelme-Agulló I, Heredia-Rizo AM, Ricard F, Oliva-Pascual-Vaca Á. Effects of the fourth ventricle compression in the regulation of the autonomic nervous system: a randomized control trial. Evid Based Complement Alternat Med. 2015;2015:1-6.

19. Touche $R$, et al. Does mobilization of the upper cervical spine affect pain sensitivity and autonomic nervous system function in patients with cervico-craniofacial pain?: a randomized-controlled trial. Clin J Pain. 2013:29:3.

20. Roy RA, Boucher JP, Comtois AS. Heart rate variability modulation after manipulation in pain-free patients vs patients in pain. J Manipul Physiol Ther. 2009;32(4):277-86.

21. Win NN, Jorgensen AMS, Chen YS, Haneline MT. Effects of upper and lower cervical spinal manipulative therapy on blood pressure and heart rate variability in volunteers and patients with neck pain: a randomized controlled, cross-over, preliminary study. J Chiropr Med. 2015:14(1):1-9.

22. Zhang J, Dean D, Nosco D, Strathopulos D, Floros M. Effect of chiropractic care on heart rate variability and pain in a multisite clinical study. J Manipul Physiol Ther. 2006;29(4):267-74.

23. Younes M, Nowakowski K, Didier-Laurent B, Gombert M, Cottin F. Effect of spinal manipulative treatment on cardiovascular autonomic control in patients with acute low back pain. Chiropr Man Ther. 2017;25(1):33.

24. Fukuda $\mathrm{H}$, et al. Cerebral metabolic changes in men after chiropractic spinal manipulation for neck pain. AlternTher Health Med. 2011;17:6.

25. Driscoll MD, Hall MJ. Effects of spinal manipulative therapy on autonomic activity and the cardiovascular system: a case study using the electrocardiogram and arterial tonometry. J Manipulative Physiol Ther. 2000;23(8):545-50.

26. Petersen N, Vicenzino B, Wright A. The effects of a cervical mobilisation technique on sympathetic outflow to the upper limb in normal subjects. Physiother Theory Pract. 1993;9(3):149-56.

27. Chiu TW, Wright A. To compare the effects of different rates of application of a cervical mobilisation technique on sympathetic outflow to the upper limb in normal subjects. Musculoskelet Sci Pract. 1996;1(4):198-203.

28. Jowsey P, Perry J. Sympathetic nervous system effects in the hands following a grade III postero-anterior rotatory mobilisation technique applied to T4: a randomised, placebo-controlled trial. Man Ther. 2010;15(3):248-53. 
29. Giles PD, Hensel KL, Pacchia CF, Smith ML. Suboccipital decompression enhances heart rate variability indices of cardiac control in healthy subjects. J Altern Complement Med. 2013;19(2):92-6.

30. Purdy WR, Frank JJ, Oliver B. Suboccipital dermatomyotomic stimulation and digital blood flow. J Am Osteopath Assoc. 1996;96(5):285.

31. Budgell B, Hirano F. Innocuous mechanical stimulation of the neck and alterations in heart-rate variability in healthy young adults. Auton. Neurosci. 2001;91(1-2):96-9.

32. Gibbons PF, Gosling CM, Holmes M. Short-term effects of cervical manipulation on edge light pupil cycle time: a pilot study. J Manipulative Physiol Ther. 2000;23(7):465-9.
33. Malik M, et al. Heart rate variability: standards of measurement, physiological interpretation, and clinical use. Eur Heart J. 1996;17(3):354-81.

\section{Publisher's Note}

Springer Nature remains neutral with regard to jurisdictional claims in published maps and institutional affiliations.
Ready to submit your research? Choose BMC and benefit from:

- fast, convenient online submission

- thorough peer review by experienced researchers in your field

- rapid publication on acceptance

- support for research data, including large and complex data types

- gold Open Access which fosters wider collaboration and increased citations

- maximum visibility for your research: over $100 \mathrm{M}$ website views per year

At BMC, research is always in progress.

Learn more biomedcentral.com/submissions 